\title{
PERCEPTION OF THE TWO-PRONGED TRIDENT BY TWO- AND THREE-DIMENSIONAL PERCEIVERS
}

\section{J. B. DEREGOWSKI I}

\author{
Institute for Social Research, University of Zambia, Lusaka
}

\begin{abstract}
The $S_{s}$ were categorized as either two-dimensional (2D) or three-dimensional (3D) perceivers depending on whether they built a $2 \mathrm{D}$ or a $3 \mathrm{D}$ model in response to a drawing. An hypothesis that there would be no difference between the two groups when asked to copy an "impossible" figure under conditions requiring little short-term memory storage, but that the $3 \mathrm{D}$ group would find the task more difficult if such storage was required was investigated and confirmed. No confirmation was obtained for another hypothesis that the absence of background would make the task of copying the impossible figure more difficult. The results suggest that the quality of a reproduction cannot be used as an indicator of presence or absence of 3D pictorial perception and confirm that the difficulties in interpretation of pictorial depth cues are experienced by some $S$ s.
\end{abstract}

The $S$ s drawn from certain cultural groups that have difficulties with three-dimensional perception of pictorial material should not find the "impossible" figures (Gregory, 1966) confusing, for the confusion only arises if one attempts to interpret a pattern of lines as depicting a three-dimensional object. When such an attempt is not made, any pattern of lines should be accepted as satisfactory. Deregowski (1968b) used the task of copying a two-pronged trident (the procedure used being similar to that described subsequently) in his experiment into depth perception in Zambian children, and the results obtained supported the aforementioned hypothesis. However, his subsequent replications suggested that $S$ s performing the task may find the two-pronged trident confusing only if a delay occurs between the examination of the drawing and the beginning of reproduction by $S$, a variable that was not considered in the original experiment. Such a suggestion gains support from Attneave's (1955) experiment, wherein it was found that for the same information content, a delayed reproduction caused much greater divergence between responses to random and symmetrical stimuli than did immediate reproduction. That is, stimuli that were difficult to organize perceptually were also found to be harder to re-

1 Requests for reprints should be sent to J. B. Deregowski, who is now at the University of Aberdeen, Aberdeen, Scotland. produce; and this difficulty increased with the time interval separating presentation from reproduction.

It has been suggested (Maistriaux, no date; Deregowski, 1968b) that the presence of background may be a contributory factor to the difficulties of pictorial perception. Assuming that the presence of a background, which does not incorporate additional depth cues, tends to make two-dimensional perception more probable, one would expect its removal to lead to three-dimensional perception and hence to greater confusion when the stimuli represent "impossible" figures.

The following hypotheses were therefore postulated :

Hypothesis 1. There will be a significant difference between two-dimensional (2D) and three-dimensional (3D) $S$ s when copying a two-pronged trident only when a period of delay between inspection of the stimulus and drawing response is introduced. The $3 \mathrm{D} S \mathrm{~s}$ will be found to have greater difficulties.

Hypothesis 2. The difficulties of $S$ s responding to the confusing figure will be greater when no stimulus background is visible than when such background is visible.

\section{Method}

\section{Experimental Plan}

Each $S$ was classified as a $2 D$ or a $3 D$ perceiver on the basis of his response to the construction tasks. He was subsequently allocated 
to one of the four possible combinations of the following experimental conditions: duration of delay (.1 or $10.0 \mathrm{sec}$ ) with either the luminous models or the drawings being used as stimuli.

\section{Construction Tasks}

Materials.-The following materials were provided for all tasks involving construction: 14 plasticine balls, $\frac{1}{2}$-in. diameter; bamboo splints varying in length by 1 -in. steps from $2 \frac{1}{2}$ in. to $7 \frac{1}{2}$ in. and forming six sets of 12 splints each, the splints within each set being equally long.

A preliminary construction task was used to introduce $S$ to the construction materials provided. A tetrahedron consisting of four plasticine balls connected by six 7-in. bamboo splints was placed on a table in front of $S$. The model was pointed out to $S$, and he was requested to build a "thing" like it using wood and "clay" (plasticine), which were also pointed out to him. When $S$ had indicated that he had completed his model, it was taken to pieces and $S$ was given his first test task.

\section{Construction Test}

Materials.-The construction materials previously described were used with a set of drawings (see Fig. 1) that were intended to embody the following depth cues: (i) overlap, (ii) size difference, and (iii) size difference and overlap.

Procedure.--The drawings were presented vertically in the aforementioned sequence in front of $S$, who was instructed: "I want you to build what you see on the picture." Any further inquiries were met with: "Just as you see on the picture." When $S$ indicated that he had completed his model, $E$ judged this model to be $2 \mathrm{D}$ or $3 \mathrm{D}$, recorded his judgments, and made a sketch of the model. The model was then taken to pieces and the next drawing was presented with the same instructions.

The criteria for $3 \mathrm{D}$ and $2 \mathrm{D}$ judgments were as follows: A response was judged to be $3 \mathrm{D}$ if all the members did not lie in parallel or nearly parallel planes separated by a distance not exceeding $\frac{1}{2}$ in.; all other responses were classified as being 2D. No difficulty was experienced in applying this criterion as no models fell within the borderline region.
Any $S$ who made a $3 \mathrm{D}$ response to all three drawings was classified as a $3 \mathrm{D} S$; all other $S$ s were classified as $2 \mathrm{D}$.

\section{Drawing Task}

Materials.-The apparatus was placed in two neighboring cubicles having an interconnecting window. One of the cubicles was used to display the stimuli while $S_{\mathrm{s}}$ sat in the other. The $S_{\mathrm{s}}$ could see the displayed stimulus by lifting a $13 \times 8$ in. flap in the screen obscuring the window. Lifting of the flap started a stop clock (Spencer, 1965) that measured the duration for which the window was uncovered in ,1-sec. units. Closure of the flap started a Birkbeck timer, which, depending on the setting used, produced an auditory signal either $.1 \mathrm{sec}$, or $10.0 \mathrm{sec}$, after closure. The display cubicle contained either three flat wire models painted with paint which reradiated ultraviolet light in visible spectrum and an ultraviolet light source or a set of three drawings (see Fig. 2) illuminated by an ordinary incandescent lamp. The models glowed orange-yellow when exposed to ultraviolet light in the otherwise dark cubicle. The drawings, which were of the same size and shape as the models, were drawn on white cardboard in India ink. Both drawings and the models were suspended in a triangular formation, the introductory stimulus (see Fig. 2a) being above the other two stimuli. The two-pronged trident hung to the left of the trident. A set of cardboard screens enabled any desired stimulus to be exposed at any time.

Procedure.-Each $S$ was shown first how the flap could be lifted. Then he was given a sheet of foolscap paper and a ball-point pen and asked to draw what he saw through the window, the introductory model being on display. He was told that he could lift the flap as often as he wished and look at the stimulus for as long as he wished, but that he must not draw while the flap was open and must wait for the signal (this was demonstrated) before beginning to draw. During this task, any misunderstandings (such as the tendency of some $S s$ who responded to drawings to draw the screens concealing the other stimuli) were resolved. Subsequently, the introductory stimulus was covered, one of the other stimuli was displayed, and $S$
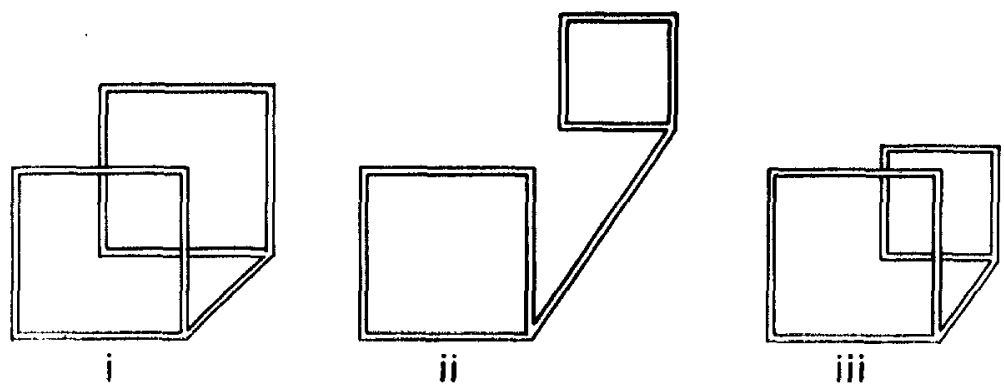

Fig. 1. Construction test stimuli. 


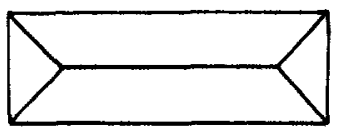

a
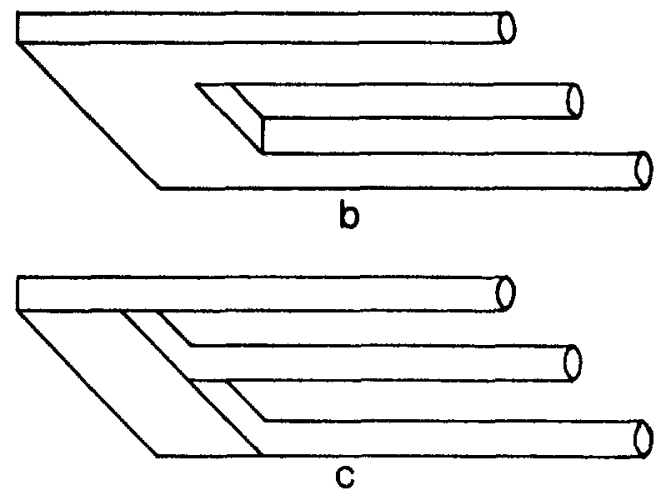

FIG. 2. Drawing task stimuli.

was asked to draw it. The order of the test stimuli was alternated so that half of the $S$ s within each group responded to each of the two possible sequences.

As soon as $S$ indicated that he considered his drawing to be finished, the total time he kept the flap open was recorded.

Subjects.-Sixty-seven boys were drawn from the third and fourth grades of two non-fee-paying primary schools in Lusaka. The sample characteristics, which excluded 3 rejected $S$ s, were: 30 Grade $4 S \mathrm{~s}, 34$ Grade $3 S \mathrm{~s}$; mean age $=10.7 \mathrm{yr}$, $S D=1.9$. The age parameters are based on 63 $S$ s, as $1 S$ did not know his age.

\section{RESULTS}

Three $S$ s had to be rejected, two because, contrary to the instructions, they included irrelevant material in the test reproductions and the third because he constructed tetrahedra (a type of response appropriate to the introductory construction task) in response to all three of the construction test drawings. The mean durations of inspection times of the acceptable $S$ s are given in Table 1 . These were not used directly in the analysis of data ; instead, for each $S$ a ratio of the difference between the time spent looking at the two-pronged trident and the time spent looking at the trident to the sum of these times was calculated. This was termed coefficient $C$ and was done to reduce inter- $S$ differences, which might have roots in the differences in ability to draw and in the standard of perfec- tion aimed at. The higher the value of this coefficient, the more difficult does $S$ find the copying of the confusing figure.

These ratios (for mean values, see Table 1) were used in an analysis of variance. The only main effect approaching significance is the delay between the closing of the flap and the signal to draw, $F(1,56)=3.20$, $p<.10$. The second-level interaction is nonsignificant, but one of the first-level interactions, that between the category of the $S \mathrm{~s}$ and the duration of delay, is $F(1,56)=$ $5.75, p<.025$. Tukey's tests, therefore, were applied, and it was found that for both background conditions, there exist significant differences in the predicted directions between the responses of 3D $S \mathrm{~s}$ in .1-sec. and 10.0 -sec. delay conditions $(p<.01$ for nonbackground conditions; $p<.05$ for background conditions), as well as between the responses of 2D $S \mathrm{~s}$ and 3D $S \mathrm{~s}$ in 10.0-sec. delay conditions $(p<.05)$. These relationships find confirmation in the comparison of the frequencies with which the responders in the combined background and nonbackground groups fell into two categories, those supporting the postulated hypothesis and those failing to support it. Application of Fisher's exact test to the data (see Table 1) yields significant results both in the case of the comparison of the responses of 3D $S$ s with those of 2D $S$ s in $10.0-\mathrm{sec}$, delay conditions $(p<.01)$ and in the case of the comparison of the 3D $S s^{\prime}$ responses in .1-sec. and $10.0-\mathrm{sec}$. conditions $(p<.025)$.

There is also a single statistically significant difference (Tukey's test, $p<.05$ ) in the .1-sec. delay condition. This is the difference between the two nonbackground groups, the 2D group having a higher coefficient $C$ value than the $3 \mathrm{D}$ group.

Three independent judges allocated drawings obtained in response to each of the experimental stimuli into three categories: good, indifferent, and bad. The data thus gained were used for the following comparisons: (a) Within each judge/stimulus combination, the frequency of the response of the 3D $S \mathrm{~s}$ was compared with that of the 2D $S \mathrm{~s}$. In no case did the difference approach statistical significance. (b) Those "bad" copies 
TABLE 1

SUMmaRy of Obtainen Data

\begin{tabular}{|c|c|c|c|c|c|}
\hline \multirow{2}{*}{$\begin{array}{c}\text { Type of } \\
S_{9}\end{array}$} & \multirow{2}{*}{ Data } & \multicolumn{2}{|c|}{.1-sec. delay } & \multicolumn{2}{|c|}{ 10.0-sec. delay } \\
\hline & & No background & Background & No background & Background \\
\hline $2 \mathrm{D}$ & $\begin{array}{l}\text { Raw scores (in sec.) } \\
\text { Mean values for TPT } \\
\text { Mean values for T } \\
\text { Coefficient } C(M) \\
\text { No. of } S \mathrm{~s} \text { taking longer to copy TPT } \\
\text { No. of other } S \mathrm{~s}\end{array}$ & $\begin{array}{l}18.5 \\
14.5 \\
.703 \\
5 \\
3\end{array}$ & $\begin{array}{l}21.4 \\
27.1 \\
-.350 \\
3 \\
5\end{array}$ & $\begin{array}{l}28.6 \\
30.4 \\
-.015 \\
3 \\
5\end{array}$ & $\begin{array}{l}41.2 \\
44.2 \\
-.175 \\
\quad 2 \\
6\end{array}$ \\
\hline $3 \mathrm{D}$ & $\begin{array}{l}\text { Raw scores (in sec.) } \\
\text { Mean values for TPT } \\
\text { Mean values for T } \\
\text { Coefficient } C(M) \\
\text { No. of } S \text { s taking longer to copy TPT } \\
\text { No. of other } S \mathrm{~s}\end{array}$ & $\begin{array}{l}13.7 \\
16.2 \\
-.650 \\
3 \\
5\end{array}$ & $\begin{array}{l}17.7 \\
19.4 \\
-.333 \\
3 \\
5\end{array}$ & $\begin{array}{l}22.1 \\
17.0 \\
1.568 \\
6 \\
2\end{array}$ & $\begin{array}{c}26.0 \\
21.0 \\
1.183 \\
7 \\
1\end{array}$ \\
\hline
\end{tabular}

Note $-\mathrm{TPT}=$ two-pronged trident figure $;=$ trident figure.

of the confusing drawing on which all three judges agreed were analyzed to see whether the difference between the number of $2 \mathrm{D}$ and $3 \mathrm{D}$ responders within the category differed from chance. It was found that the category contained $152 \mathrm{D}$ and $153 \mathrm{D} S \mathrm{~s}$. The other categories were too small to permit such analysis.

\section{Discussion}

The results support the first hypothesis. It seems that when very little retention is required, $S$ s from both populations experience no special difficulties with the two-pronged trident. However, when $S$ s are required to remember the stimuli, even for a relatively short time, the $3 \mathrm{D} S \mathrm{~s}$, who presumably find the two-pronged trident confusing, find its reproduction significantly more difficult than do the $2 \mathrm{D} S \mathrm{~s}$. This suggests that depth perception once acquired cannot be easily suppressed, for if it could, the $3 \mathrm{D} S \mathrm{~s}$ would have probably taken advantage of this. As a further support for the previous suggestion can be adduced the absence of $2 \mathrm{D} / 3 \mathrm{D}$ borderline responses in the construction task, which was observed both here and previously (Deregowski, 1968a, 1968b), as well as the consistency of $S \mathrm{~s}$ in making one of the two possible types of response. Thus of the $64 S \mathrm{~s}$ tested, only 6 gave responses that were not either all 3D or all 2D.

It must be noted that the $2 \mathrm{D} / 3 \mathrm{D}$ dichotomization used here is not synonymous with the division of $S$ s that can be arrived at on the basis of Hudson's $(1960,1967)$ test, for it has been shown (Deregowski, 1968a, 1968b) that the construction test differs from Hudson's test by evoking a larger number of 3D responses. In this sense, therefore, pictorial depth perception is not a yes/no phenomenon; Hudson's test pictures, which are meaningful representations of a hunting scene, are, however, of an entirely different nature from the stimuli used here. It is difficult, therefore, to say to what extent the two tests sample the same phenomena.

Insofar as the construction test and the drawing task employed here reinforce each other, the results suggest that a proportion of the population sampled is incapable of perceiving depth in simple geometrical figures.

The second hypothesis did not gain support from the data. In the case of the stimuli employed, the background appears to play no significant part in perception of the stimuli used. It may be, however, that it is of consequence in a different type of pictures.

It appears that the drawings of the 3D $S \mathrm{~s}$ do not differ significantly from those obtained from the 2D $S$ s and hence that the quality of reproduction is not affected by the perceptual style of $S$. Given sufficient time, both groups are capable of producing drawings of comparable quality.

Examination of the drawings reveals a large range of accuracy of representation extending from correct copy to a highly impressionistic depiction of the trident representing an object with as many as six prongs. These fantastic distortions probably correspond to similar distortions in response to the construction task observed both here and previously (Deregowski, 1968a, 1968b). Further, the drawings are frequently both oddly oriented (the trident is often rotated through $90^{\circ}$ ) and oddly placed 
relative to the sheet on which they were drawn. This is probably the same phenomenon described by Hudson $(1962,1967)$ and not specially related to the task used here.

\section{REFERENCES}

Attneave, F. Symmetry, information and memory for patterns. American Journal of Psychology, 1955, 68, 209-222.

Deregowskr, J. B. Difficulties in pictorial depth perception in Africa. British Journal of Psychology, 1968, 59, 195-204. (a)

DeREgowskr, J. B. Investigation into pictorial perception with special reference to Central Africa. Unpublished doctoral dissertation, University of London, 1968. (b)
Gregory, R. L. Visual illusions. In B. M. Foss (Ed.), New horizons in psychology. Harmondsworth, Middlesex: Penguin Books, 1966.

Hudsos, W. Pictorial depth perception in subcultural groups in Africa. Journal of Social Psychology, 1960, 52, 183-208.

Hudson, W. Pictorial perception and educational adaptation in Africa. Psychologia Africana, 1962, 9, 226-239.

Hudson, W. The study of the problem of pictorial perception among unacculturated groups. International Journal of Psychology, 1967, 2, 89-107.

MAISTRIAUX, R. L'intelligence noire et son destin. Bruxelles: Les editions de problemes d'Afrique Centrale, no date.

SPENCER, J. An inexpensive digital stop-clock. British Journal of Psychology, 1965, 56, 317-319.

(Received December 13, 1968) 